\title{
Inhibitory Effect of Scopoletin on U46619-induced Platelet Aggregation through Regulation of $\mathrm{Ca}^{2+}$ Mobilization
}

\author{
Dong-Ha Lee ${ }^{\dagger, *}$ \\ Department of Biomedical Laboratory Science, Molecular Diagnostics Research Institute, \\ Namseoul University, Cheonan 31020, Korea
}

\begin{abstract}
Platelet aggregation is essential for hemostatic process in case of blood vessels damages. However, excessive platelet aggregation can cause cardiovascular disorders including atherosclerosis, thrombosis and myocardial infarction. Scopoletin is usually found in the roots of genus Scopolia or Artemisia, and is known to have anticoagulant and anti-malarial effects. This study investigated the effect of scopoletin on human platelet aggregation induced by U46619, an analogue of thromboxane $\mathrm{A}_{2}\left(\mathrm{TXA}_{2}\right)$. Scopoletin had anti-platelet effects by down-regulating $\mathrm{TXA}_{2}$ and intracellular $\mathrm{Ca}^{2+}$ mobilization $\left(\left[\mathrm{Ca}^{2+}\right]_{\mathrm{i}}\right)$, the aggregation-inducing molecules generated in activated platelets. On the other hand, scopoletin increased the levels of cyclic adenosine monophosphate (cAMP) and cyclic guanosine monophosphate (cGMP), which are known to be intracellular $\mathrm{Ca}^{2+}$ antagonists. This resulted in inhibition of fibrinogen binding to $\alpha \mathrm{IIb} / \beta_{3}$ in U46619-induced human platelet aggregation. In addition, scopoletin inhibited the release of adenosine trisphosphate (ATP) in dose-dependent manner. This result means that the aggregation amplification activity through the granule secretion in platelets was suppressed by scopoletin. Therefore, we demonstrated that scopoletin has a potent antiplatelet effect and is highly likely to prevent platelet-derived vascular disease.
\end{abstract}

Key Words: Scopoletin, Platelet aggregation, Intracellular $\mathrm{Ca}^{2+}$, Fibrinogen binding

\section{서 론}

혈소판 응집은 혈관이 손상되었을 때 지혈 마개를 형성 하는데 있어서 필수적인 반응이다. 특히, 혈소판에서 세포 질 내 $\mathrm{Ca}^{2+}\left(\left[\mathrm{Ca}^{2+}\right]_{\mathrm{i}}\right)$ 농도는 혈소판 응집의 활성화에 핵심 적인 역할을 하며, $\left[\mathrm{Ca}^{2+}\right]_{\mathrm{i}}$ 은 inositol 1,4 , s-trisphosphate $\left(\mathrm{IP}_{3}\right)$ 에 의해 내부 저장소인 dense tubular system에서부터 수용 체를 통해 세포질 내로 동원된다고 알려져 있다(Furuichi and Mikoshiba, 1995). 증가된[Ca $\left.{ }^{2+}\right]_{\mathrm{i}}$ 는 혈소판막에 위치한 phosatidylinositiol 4,5-bisphosphate $\left(\mathrm{PIP}_{2}\right)$ 가 분해되면서 생성
되는 Diacyglycerol (DG)과 함께 $\mathrm{Ca}^{2+} /$ calmodulin 복합체에 의존적인 myosin light chain $(20 \mathrm{kDa})$ 의 인산화와 protein kinase C (PKC)에 의존적인 plecktrin (40 또는 $47 \mathrm{kDa})$ 의 인 산화를 일으킴으로써 세포골격 단백질의 재배열을 유도하 고, 결과적으로 혈소판을 응집시키는 것으로 알려져 있다 (Furuichi and Mikoshiba, 1995). 또한, DG는 DG lipase와 monoacyglycerol $(\mathrm{MG})$ lipase에 의해 순차적으로 가수 분해 되어 arachidonic acid를 거쳐 Thromboxane $\mathrm{A}_{2}\left(\mathrm{TXA}_{2}\right)$ 로 전 환된다(Ohkubo et al., 1996). $\mathrm{TXA}_{2}$ 는 혈소판을 활성화시켜 분비 및 형태 변화를 유도하는 것으로 알려져 있다(Saitoh et al., 1986). 실제로, $\mathrm{TXA}_{2}$ 의 안정한 유사체인 U46619 (9,

Received: February 21, 2019 / Revised: March 30, 2019 / Accepted: May 22, 2019

*Professor.

†Corresponding author: Dong-Ha Lee. Department of Biomedical Laboratory Science, Molecular Diagnostics Research Institute, Namseoul University, 91, Daehak-ro, Seonghwan-eup, Seobuk-gu, Cheonan-si, Chungcheongnam-do 31020, Korea.

Tel: +82-41-580-2148, Fax: +82-41-580-2932, e-mail: dhlee@nsu.ac.kr

(C) The Korean Society for Biomedical Laboratory Sciences. All rights reserved.

(c) This is an Open Access article distributed under the terms of the Creative Commons Attribution Non-Commercial License (http://creativecommons.org/licenses/by-nc/3.0/) which permits unrestricted non-commercial use, distribution, and reproduction in any medium, provided the original work is properly cited. 
11-dideoxy-9a.la-methanoepoxyprostaglandin $\mathrm{F} 2 \mathrm{a})$ 는 $\left[\mathrm{Ca}^{2+}\right]_{\mathrm{i}}$ 를 상승시키면서 myosin light chain와 pleckstrin의 인산 화를 증가시키는 우수한 혈소판 응집 유도제로 이용된다 (Cattanco et al., 1991; Su et al., 1999). 이러한 현상은 혈액 내 지혈 반응의 정상적인 과정이지만 혈소판 응집이 과도하 게 일어날 경우에 동맥 경화와 같은 다양한 혈관 질환의 원인이 되기도 한다. 따라서, 적절하게 혈소판 응집을 억 제하는 것이 심혈관계 질환을 예방하는 유용한 접근방법 이 될 수 있다(Cattanco et al., 1991; Su et al., 1999).

Verapamil과 theophylline은 혈소판 응집의 필수 요소인 $\left[\mathrm{Ca}^{2+}\right]_{\mathrm{i}}$ 를 감소시키는 cyclic adenosine monophosphate (cAMP) 의 수준을 높임으로써 항혈소판 기능을 한다. 또한, molsidomine과 nitroprusside 같은 혈관확장제와 zaprinast와 erythro-9-(2-hydroxy-3-nonyl) adenine과 같은 cyclic guanosine monophosphate (cGMP) phosphodiesterase (PDE) 억제 제는 혈소판에서 cGMP 수준을 높인다(Menshikov et al., 1993). cAMP와 cGMP의 항혈소판 효과는 기질 단백질 vasodilator-stimulated phosphoprotein (VASP)을 인산화시키 는 cAMP와 cGMP-의존성 단백질 kinase(각각 A-kinase와 G-kinase)에 의해 매개된다(Kawada et al., 1997; Calderwood et al., 2000). VASP는 actin 결합 단백질로서 분비와 부착에 길항작용을 하며, $\mathrm{VASP}$ 의 인산화는 $\alpha \mathrm{Ilb} / \beta_{3}$ 의 활성에 기여 하는 VASP 친화도를 억제하는 것에 관련된다고 알려져 있다(Smolenski et al., 1998).

Scopolia 또는 Artemisia 속 식물의 뿌리에서 흔히 발견 되는 Scopoletin은 말라리아 방지 및 응고 방지 효과가 있는 것으로 알려져 있다(Obasi et al., 1994; Towler and Weathers, 2015). 그러나, 혈소판 응집에서의 scopoletin의 역할 및 U46619에 의해 유발되는 사람 혈소판 응집에 대 한 scopoletin의 기전에 대해서는 알려진 바가 없다. 본 연 구는 scopoletin의 항혈소판 작용을 명확히 하기 위해 scopoletin이 U46619가 유도한 혈소판 응집과 관련된 다양한 인자에 미치는 영향을 확인하고자 하였다.

\section{재료 및 방법}

\section{실험재료}

Scopoletin (PIN:7-Hydroxy-6-methoxy-2H-1-benzopyran-2one, Chemical formula: $\mathrm{C}_{10} \mathrm{H}_{8} \mathrm{O}_{4}$, Molar mass: $192.16 \mathrm{~g} / \mathrm{moL}$ ) 는 Avention Corporation (Seoul, Korea)에서 구입하였다(Fig. 1). U46619는 Chrono-Log Corporation (Havertown, PA, USA) 에서 입수하였다. $\mathrm{TXB}_{2}$, ATP, cAMP 및 cGMP enzymeimmu-

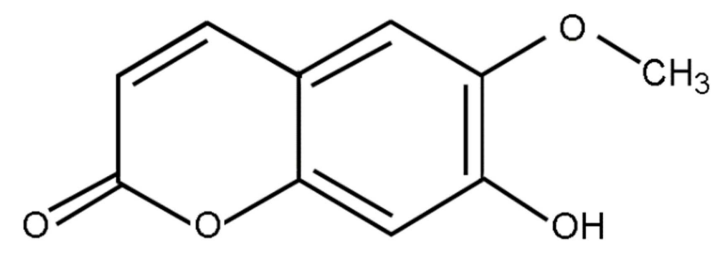

Fig. 1. The structure of scopoletin. PIN:7-Hydroxy-6-methoxy-2H1-benzopyran-2-one, Chemical formula: $\mathrm{C}_{10} \mathrm{H}_{8} \mathrm{O}_{4}$, Molar mass: $192.16 \mathrm{~g} / \mathrm{moL}$.

noassay (EIA) kit는 Cayman Chemical (AnnArbor, MI, USA)에 서 구입했다. Fura 2-AM 및 Fibrinogen Alexa Fluor 488 접합 체는 Invitrogen (Eugene, OR, USA)으로부터 구입하였다.

\section{사람 세척 혈소판 제조}

사람 혈소판 풍부 혈장(platelet rich plasma, PRP)은 한국 적십자 혈액원(Suwon, Korea)에서 입수하였다. 이전에 발 표된 방법(Kwon and Lee, 2017)에 따라서 세척 혈소판(10 cells $/ \mathrm{mL}$ )을 준비했습니다. PRP를 $1,300 \mathrm{G}$ 에서 10 분 동안 원심 분리하여 혈소판을 획득하였고, 이것을 세척 완충액 (138 mM NaCl, $2.7 \mathrm{mM} \mathrm{KCl}, 12 \mathrm{mM} \mathrm{NaHCO}, 0.36 \mathrm{mM}$ $\mathrm{NaH}_{2} \mathrm{PO}_{4}, 5.5 \mathrm{mM}$ glucose 및 $1 \mathrm{mM}$ EDTA, $\mathrm{pH}$ 6.9)으로 2회 세척하였다. 세척된 혈소판을 $10^{8}$ cells $/ \mathrm{mL}$ 의 최종 농도로 현탁 완충액(138 mM NaCl, $5.5 \mathrm{mM}$ 글루코스, $2.7 \mathrm{mM}$ $\mathrm{KCl}, 12 \mathrm{mM} \mathrm{NaHCO}, 0.36 \mathrm{mM} \mathrm{NaH} \mathrm{PO}_{4}, 0.49 \mathrm{mM} \mathrm{MgCl}_{2}$ 및 $0.25 \%$ gelatin, $\mathrm{pH}$ 7.4)에 현탁시켰다. 저온에서 혈소판 응집이 일어나는 것을 피하기 위해 모든 절차를 $25^{\circ} \mathrm{C}$ 서 수행하였다. 이 실험은 남서울대학교의 Institutional Review Board (1041479-HR-201803-003)의 승인을 받아 수행하였다.

\section{혈소판 응집능 및 $\mathrm{TXA}_{2}$ 생성량 측정}

세척 혈소판 $\left(10^{8}\right.$ cells $\left./ \mathrm{mL}\right)$ 을 $37^{\circ} \mathrm{C}$ 에서 3 분간 배양하고, $2 \mathrm{mM}$ 의 $\mathrm{CaCl}_{2}$ 를 첨가한 후, $\mathrm{U} 46619(0.5 \mu \mathrm{M})$ 로 응집을 유도하여 5 분 동안 확인하였다. 응집은 $1,000 \mathrm{rpm}$ 에서 aggregometer (Chrono-Log, Corp., Havertown, PA, USA)를 사용하여 측정하였다. 각각의 응집능은 빛 투과율이 증가 되는 정도로 평가되었다. $\mathrm{TXA}_{2}$ 생성량은 $\mathrm{TXA}_{2}$ 의 안정한 대사 산물인 $\mathrm{TXB}_{2}$ 의 양으로 확인하였고, ice-cold EDTA $(5 \mathrm{mM})$ 및 indomethacin $(0.2 \mathrm{mM})$ 을 첨가하여 반응을 중단 시킨 후, $\mathrm{TXB}_{2} \mathrm{EIA}$ kit (Cayman Chemical)를 사용하여 측 정하였다. 


\section{세포질 내 $\mathrm{Ca}^{2+}\left(\left[\mathrm{Ca}^{2+}\right]_{i}\right)$ 의 측정}

$\mathrm{PRP}$ 를 $5 \mu \mathrm{M}$ 의 Fura 2-AM과 함께 $37^{\circ} \mathrm{C}$ 에서 60 분 동안 배양하였다. Fura 2-AM은 빛에 민감하기 때문에 PRP가 들 어있는 튜브를 알루미늄 호일로 덮은 상태를 유지하였다. 위에 명시한 절차를 사용하여 Fura 2로 충전된 세척 혈소 판 $\left(10^{8}\right.$ cells $\left./ \mathrm{mL}\right)$ 를 제조하고, $2 \mathrm{mM} \mathrm{CaCl}$ 존재 하에 $37^{\circ} \mathrm{C}$ 에서 3분간 항온 처리한 후, $\mathrm{U} 46619(0.5 \mu \mathrm{M})$ 를 처리하여 5 분 동안 확인하였다. Fura 2 의 형광은 분광 형광 측정기 (SFM 25, BioTeck Instrument, Italy)를 사용하여 측정하였고, $\left[\mathrm{Ca}^{2+}\right]_{\mathrm{i}}$ 결과는 기존 논문의 방법을 사용하여 계산하였다 (Schaeffer and Blaustein, 1989).

\section{Cyclic nulceotides (cAMP 및 cGMP) 생성량 측정}

세척 혈소판 $\left(10^{8}\right.$ cells $\left./ \mathrm{mL}\right)$ 을 $37^{\circ} \mathrm{C}$ 에서 3 분간 배양하고, $2 \mathrm{mM}$ 의 $\mathrm{CaCl}_{2}$ 를 첨가한 후, $\mathrm{U} 46619(0.5 \mu \mathrm{M})$ 로 자극하여 5 분 동안 응집을 유도하였다. $1 \mathrm{M} \mathrm{HCl}$ 를 첨가하여 반응을

A

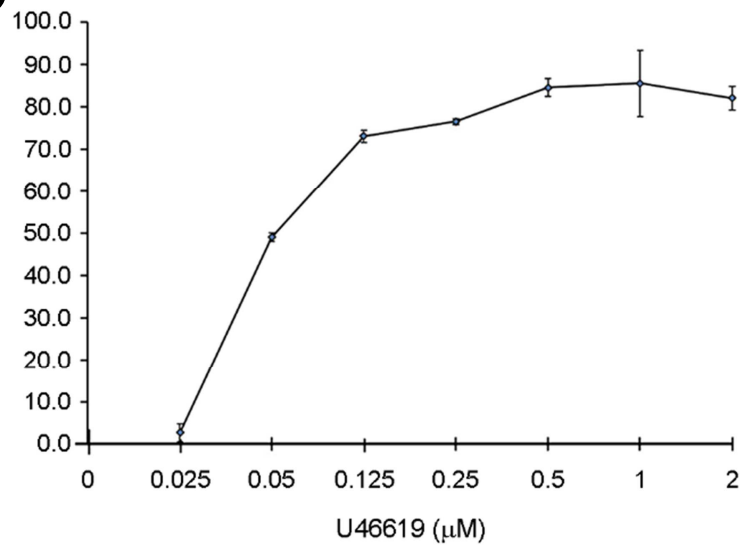

C

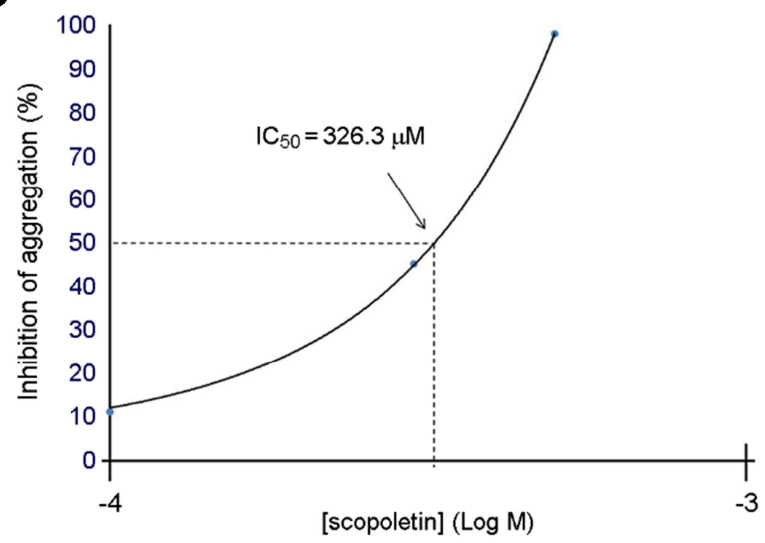

종결하였고, cAMP 및 cGMP를 EIA kit를 사용하여 Synergy HT Multi-Model Microplate Reader (BioTek Instruments, Winooski, VT, USA)를 통해 측정하였다.

\section{$\alpha \mathrm{llb} / \beta_{3}$ 에 대한 fibrinogen 결합능 측정}

Alexa Flour 488-human fibrinogen $(30 \mu \mathrm{g} / \mathrm{mL})$ 이 결합된 세척 혈소판 $\left(10^{8}\right.$ cells $\left./ \mathrm{mL}\right)$ 을 $2 \mathrm{mM}$ 의 $\mathrm{CaCl}_{2}$ 를 첨가한 후, $\mathrm{U} 46619(0.5 \mu \mathrm{M})$ 로 자극하였다. 반응을 종결시키기 위해 $0.5 \%$ paraformaldehyde가 함유된 phosphate-buffered saline $(\mathrm{PBS}, \mathrm{pH}$ 7.4)를 첨가하였다. 이 과정은 빛을 차단하면서 수행되었고, fibrinogen 결합능은 유세포분석기(BD Biosciences, San Jose, CA, USA)를 사용하여 수행하였으며, CellQuest software (BD Biosciences)로 분석하였다.

\section{ATP 방출량 측정}

세척 혈소판 $\left(10^{8}\right.$ cells $\left./ \mathrm{mL}\right)$ 에 $2 \mathrm{mM}$ 의 $\mathrm{CaCl}_{2}$ 를 첨가한 후, $\mathrm{U} 46619(0.5 \mu \mathrm{M})$ 로 자극하여 5분 동안 응집을 유도하였

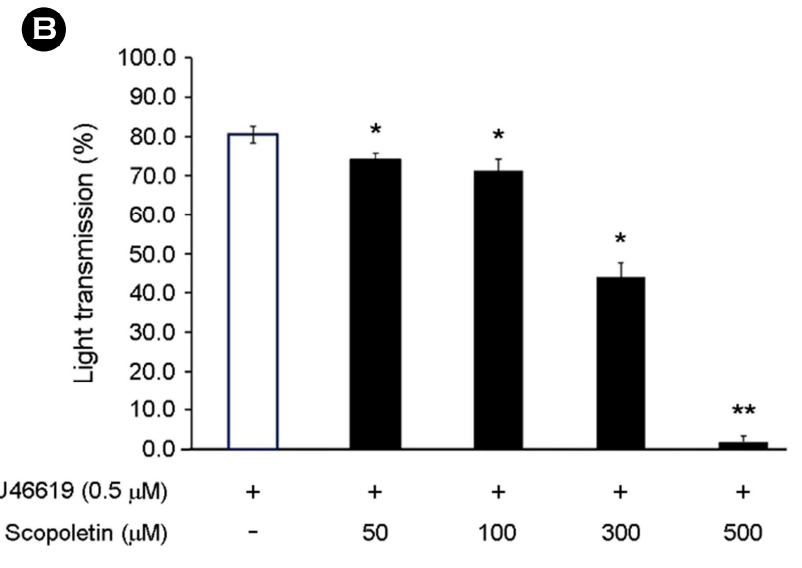

Fig. 2. Effects of scopoletin on platelet aggregation. (A) Concentration threshold of U46619 on human platelet aggregation. (B) Effects of scopoletin on platelet aggregation stimulated by U46619. (C) Half-maximal inhibitory concentration $\left(\mathrm{IC}_{50}\right)$ value of scopoletin in U46619-stimulated human platelet aggregation. Data are expressed as means $\pm \operatorname{SD}(n=4) .{ }^{*} P<0.05,{ }^{* *} P<0.001$ compared with the U46619-stimulated platelets. 
A

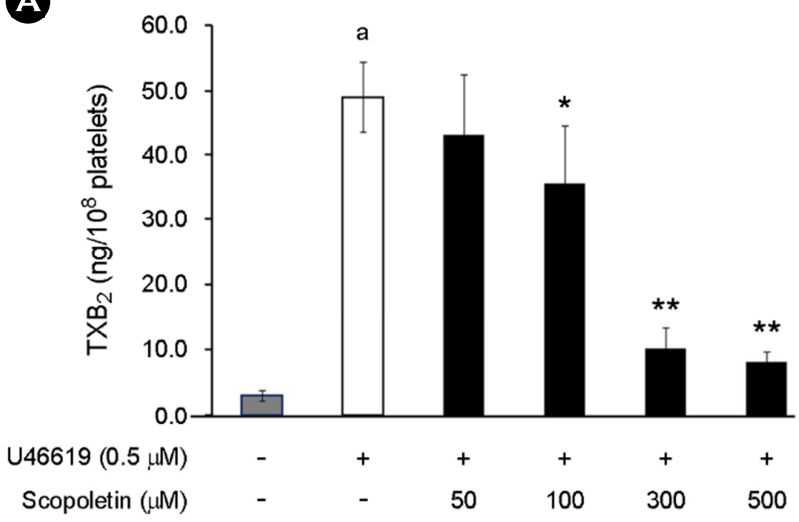

B

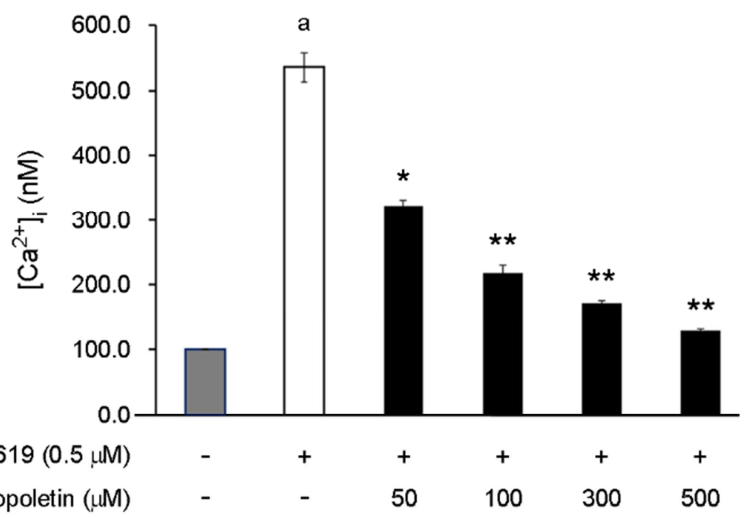

Fig. 3. Effects of scopoletin on $\mathrm{TXB}_{2}$ production and $\left[\mathrm{Ca}^{2+}\right]_{\mathrm{i}}$ (A) Effects of scopoletin on $\mathrm{TXB}_{2}$ production stimulated by U46619. (B) Effects of scopoletin on $\left[\mathrm{Ca}^{2+}\right]_{\mathrm{i}}$ stimulated by U46619. Data are expressed as means $\pm \mathrm{SD}(n=4) .{ }^{\mathrm{a}} P<0.05$ compared with no-stimulated platelets, ${ }^{*} P<0.05,{ }^{* *} P<0.001$ compared with the U46619-stimulated platelets.

다. 반응이 종결되고 $4^{\circ} \mathrm{C}$ 에서 10 분간 $1,000 \mathrm{G}$ 로 원심 분리 한 후, 상등액을 분리하여 ATP 방출량 측정에 사용하였 다. ATP 방출량은 luminometer (BioTek Instruments로 ATP assay kit를 사용하여 측정하였다.

\section{통계 분석}

결과는 평균 \pm 표준 편차로 나타냈고, 통계 분석은 양측 의 unpaired Student's $t$-test 또는 ANOVA를 사용하여 적절 하게 수행되었다. ANOVA에 따른 집단 평균 간에 유의한 차이가 있다면 각 집단을 Scheffe의 방법으로 비교하였다.

\section{결 과}

\section{혈소판 응집능에 대한 scopoletin의 효과}

$\mathrm{U} 46619$ 에 의해 유도되는 사람 혈소판의 응집도를 다양 한 농도에서 확인하였고, $0.5 \mu \mathrm{M}$ 이상에서 최대로 응집을 유도하는 것을 확인하였다(Fig. 2A). 따라서, $0.5 \mu \mathrm{M} \mathrm{U} 46619$ 을 응집을 유도하는 물질의 농도로 사용하였다. Fig. 2B에 나타낸 바와 같이, U46619에 의해 유도 된 혈소판 응집은 $80.5 \pm 2.1 \%$ 이었지만, scopoletin $(50,100,300$ 및 $500 \mu \mathrm{M})$ 은 혈소판 응집을 $74.0 \pm 1.7,71.3 \pm 2.9,44.0 \pm 3.6$ 및 $1.8 \pm$ $1.5 \%$ 으로 유의하게 억제하였다. 그리고, scopoletin의 halfmaximal inhibitory concentration $\left(\mathrm{IC}_{50}\right)$ 은 약 $326.3 \mu \mathrm{M}$ 이었 으며(Fig. $2 \mathrm{C}$ ), 혈소판에 미치는 scopoletin의 독성은 유의 한 효과가 없음을 확인하였다(Data not shown). 이 결과는 scopoletin이 세포독성이 없이 혈소판 응집 억제제로서 기 능할 수 있음을 의미한다.

\section{Scopoletin이 $\mathrm{TXB}_{2}$ 와 $\left[\mathrm{Ca}^{2+}\right]_{i}$ 에 미치는 영향}

손상이 없는 상태의 혈소판에서 $\mathrm{TXB}_{2}$ 의 양은 $3.0 \pm 0.8$ $\mathrm{ng} / 10^{8}$ 혈소판이었고 혈소판을 U46619 $(0.5 \mu \mathrm{M})$ 로 자극 했을 때 $48.9 \pm 5.4 \mathrm{ng} / 10^{8}$ cells으로 크게 증가했다. 그러나, scopoletin $(50,100,300$ 및 $500 \mu \mathrm{M})$ 은 증가한 $\mathrm{TXB}_{2}$ 의 양을 농도 의존적으로 유의하게 감소시켰다(Fig. 3A). 또한, Fig. $3 \mathrm{~B}$ 에서 볼 수 있듯이, scopoletin $(50,100,300$ 및 $500 \mu \mathrm{M})$ 은 $\mathrm{U} 46619$ 에 의해 증가된[Ca $\left.\mathrm{Ca}^{2+}\right]_{\mathrm{i}}$ 를 강력하게 억제하였다.

\section{Scopoletin이 cAMP 및 cGMP 생성에 미치는 영향}

$\mathrm{cAMP}$ 와 cGMP 모두 $\left[\mathrm{Ca}^{2+}\right]_{\mathrm{i}}$ 을 감소시킴으로써 혈소판 응집의 음성 조절자로 기능한다고 알려져 있다(Kawada et al., 1997). 따라서, scopoletin이 cAMP 또는 cGMP의 생성에 영향을 미치는지 확인하였다. Fig. $4 \mathrm{~A}$ 에 나타낸 바와 같이, scopoletin은 cAMP 수준을 $4.2 \pm 0.2 \mathrm{pmoL} / 10^{8}$ cells에서 7.3 $\pm 0.7 \mathrm{pmoL} / 10^{8}$ cells으로 강하게 증가시켰다. 그리고, cGMP 도 scopoletin에 의해 $5.9 \pm 0.4 \mathrm{pmoL} / 10^{8}$ cells에서 $16.3 \pm 2.1$ $0.4 \mathrm{pmoL} / 10^{8}$ cells으로 크게 증가되었다(Fig. 4B). 이러한 결과는 scopoletin이 U46619로 유도된 혈소판에서 cAMP 및 cGMP의 생성을 증가시킴으로써 응집억제에 기능하다 는 것을 의미한다.

Scopoletin이 $\alpha \mathrm{llb} / \beta_{3}$ 에 대한 fibrinogen 결합능에 미치 는 영향

세포질 내 cyclic nulceotides의 생성증가는 $\alpha \mathrm{Illb} / \beta_{3}$ 에 대한 fibrinogen 결합을 억제함으로써 혈소판 활성화를 억제한 
A

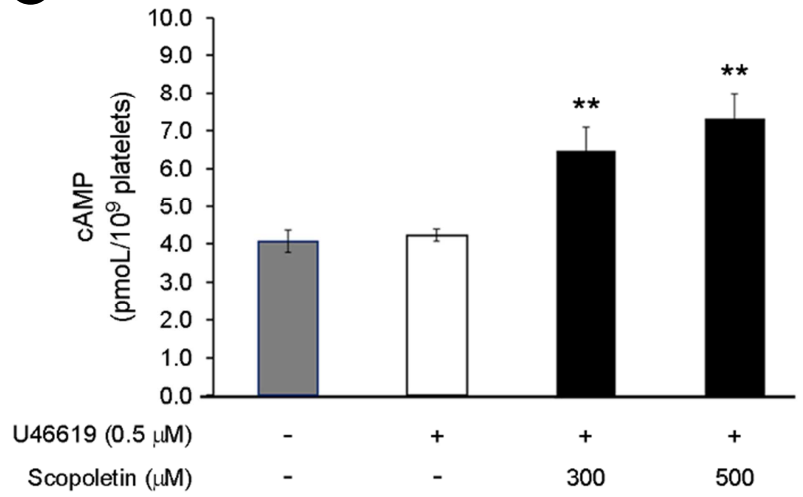

B

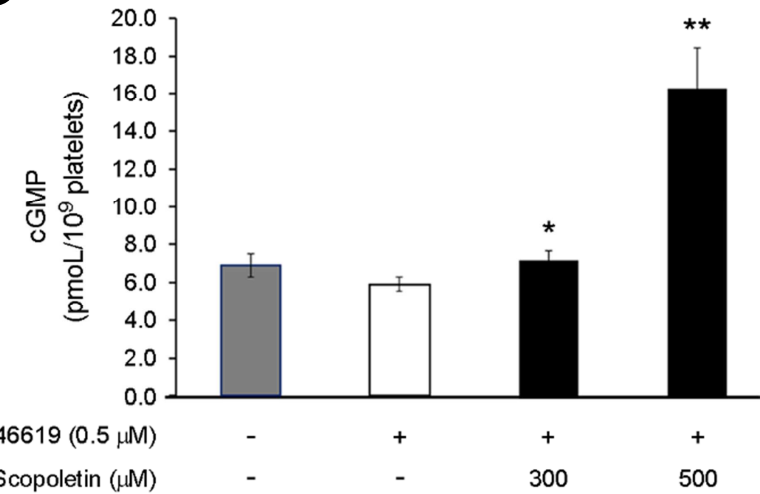

Fig. 4. Effects of scopoletin on cyclic nucleotides production. (A) Effects of scopoletin on cAMP production stimulated by U46619. (B) Effects of scopoletin on cGMP production stimulated by U46619. Data are expressed as means $\pm \mathrm{SD}(n=4) .{ }^{*} P<0.05,{ }^{* *} P<0.001$ compared with the U46619-stimulated platelets.

A
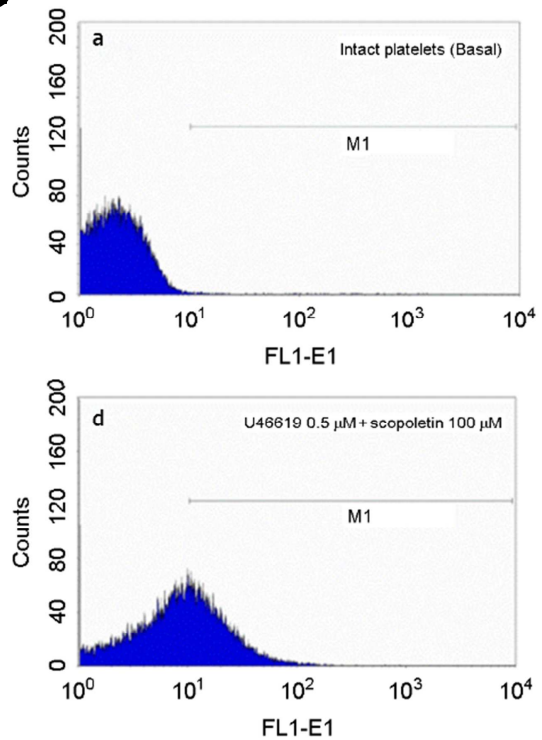
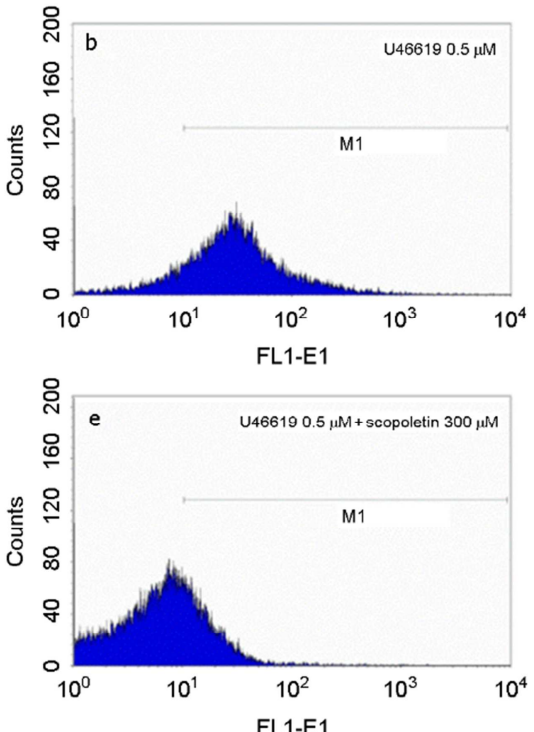
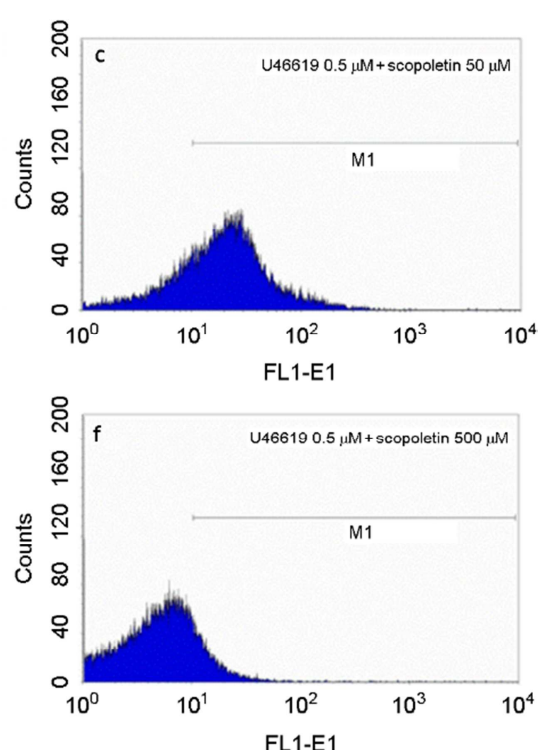

B

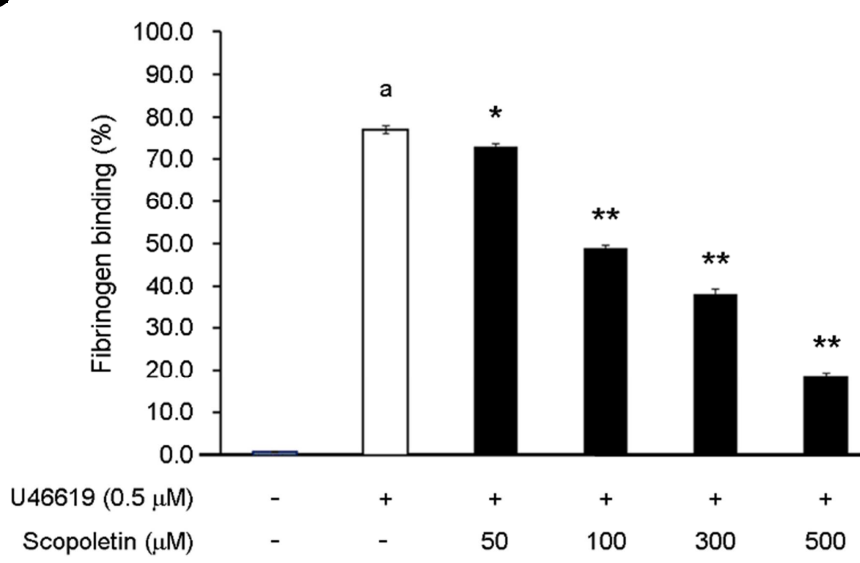

Fig. 5. Effects of scopoletin on fibrinogen binding. (A) Effects of scopoletin on fibrinogen binding. Stimulated by U46619. a, Intact platelets; b, U46619 $(0.5 \mu \mathrm{M})$; c, U46619 $(0.5 \mu \mathrm{M})+$ scopoletin $(50 \mu \mathrm{M}) ; \mathrm{d}, \mathrm{U} 46619$ $(0.5 \mu \mathrm{M})+$ scopoletin $(100 \mu \mathrm{M}) ; \mathrm{e}, \mathrm{U} 46619(0.5 \mu \mathrm{M})$ + scopoletin $(300 \mu \mathrm{M})$; f, U46619 $(0.5 \mu \mathrm{M})+$ scopoletin $(500 \mu \mathrm{M})$. (B) Effects of scopoletin on U46619stimulated fibrinogen binding (\%). These data were expressed as the means $\pm \mathrm{SD}(n=4),{ }^{\mathrm{a}} P<0.05$ compared with no-stimulated platelets, ${ }^{*} P<0.05,{ }^{* * *} P<0.001 \mathrm{com}$ pared with the U46619-stimulated platelets. 


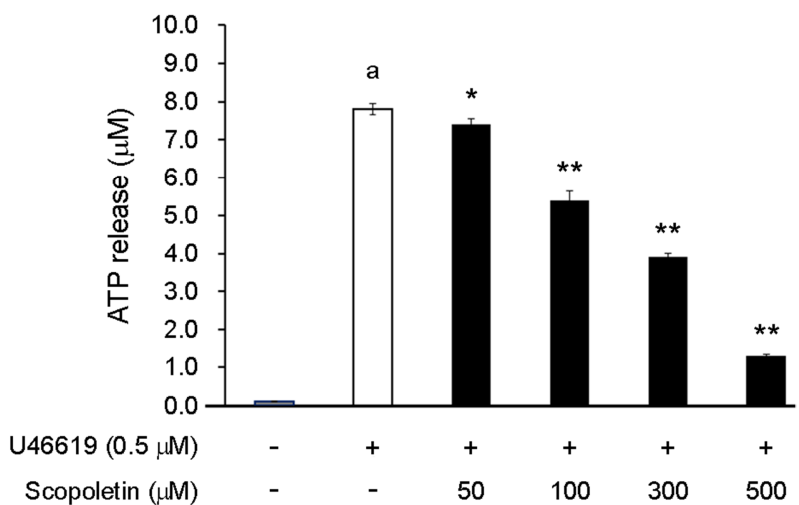

Fig. 6. Effects of scopoletin on ATP release. Data are expressed as means $\pm \mathrm{SD}(\mathrm{n}=4) .(n=4),{ }^{\mathrm{a}} P<0.05$ compared with no-stimulated platelets, ${ }^{*} P<0.05,{ }^{* *} P<0.001$ compared with the U46619-stimulated platelets.

다고 알려져 있다(Horstrup et al., 1994; Barragan et al., 2003). 따라서, scopoletin이 $\alpha \mathrm{IIb} / \beta_{3}$ 에 결합하는 fibrinogen을 억제 하는지 확인하였다. Fig. 5A에서 볼 수 있듯이, U46619는 손상이 없는 혈소판과 비교하여 $\alpha \mathrm{IIb} / \beta_{3}$ 에 결합하는 fibrinogen을 $0.7 \pm 0.1 \%$ 에서 $76.9 \pm 0.9 \%$ 로 강력하게 증가시켰다. 그러나, scopoletin은 $\mathrm{U} 46619$ 에 의해 증가된 $\alpha \mathrm{IIb} / \beta_{3}$ 에 대한 fibrinogen의 결합능을 최대 $18.8 \pm 0.6 \%$ 까지 농도 의존적으 로 강하게 억제하였다(Fig. 5B).

\section{Scopoletin이 ATP 방출량에 미치는 영향}

Fig. 6에 나타낸 바와 같이, U46619가 유도한 혈소판에 서의 ATP 수준은 손상이 없는 혈소판에서의 결과와 비 교하였을 때 약 78 배가 높은 $7.8 \pm 0.2 \mu \mathrm{M}$ 이었다. 그러나, scopoletin $(50,100,300$ 및 $500 \mu \mathrm{M})$ 은 U46619에 의해 증가 된 ATP 방출을 $7.4 \pm 0.2,5.4 \pm 0.2,3.9 \pm 0.1$ 및 $1.3 \pm 0.1 \mu \mathrm{M}$ 까지 농도 의존적으로 억제하였다. Scopoletin $(500 \mu \mathrm{M})$ 은 $\mathrm{U} 46619$ 에 의한 ATP 방출량을 $83.3 \%$ 의 억제율로 강력하 게 억제한 것이다.

\section{고 찰}

혈소판의 활성화가 일어날 때, phospholipase C- $\gamma_{2}$ (PLC- $\left.\gamma_{2}\right)$ 는 혈소판막에서 phosphatidylinositol 4,5-bisphosphate ( $\left.\mathrm{PIP}_{2}\right)$ 를 $\mathrm{IP}_{3}$ 와 diacylglycerol (DG)로 가수분해한다. 생성된 $\mathrm{IP}_{3}$ 는 dense tubular system으로부터 $\mathrm{Ca}^{2+}$ 동원을 유도하고, $\mathrm{DG}$ 는 DG-의존성 protein kinase $\mathrm{C}$ 를 활성화시킨다(Berridge and Irvine, 1989). 증가된 $\left[\mathrm{Ca}^{2+}\right]_{\mathrm{i}}$ 는 $\mathrm{Ca}^{2+} /$ calmodulin 의존성 단백
질인 myosin light chain $(20 \mathrm{kDa})$ 및 pleckstrin(40 또는 47 $\mathrm{kDa})$ 의 인산화를 초래하여 결과적으로 혈소판 응집을 유 도한다(Nishikawa et al., 1980). 또한, thromboxane $\mathrm{A}_{2}\left(\mathrm{TXA}_{2}\right)$ 는 혈소판 응집 및 후속 혈소판 활성화를 자극하는 강력 한 혈관 수축제로서, cyclooxygenase (COX)와 thromboxane A synthase (TXAS)와 같은 효소의 작용에 의해 arachidonic acid로부터 $\mathrm{PGH}_{2}$ 를 거쳐 생성된다(Okwu et al., 1992). 본 연구에서, scopoletin은 사람 혈소판에서 $\mathrm{TXA}_{2}$ 생성을 농 도 의존적으로 감소시켰고, 그 결과 $\left[\mathrm{Ca}^{2+}\right]_{\mathrm{i}}$ 를 농도 의존적 으로 억제하여 최종적으로 혈소판 응집을 억제하였다. 이 는 TXA ${ }_{2}$ 의 안정한 유사체인 U46619 (9,11-dideoxy-9a.lamethanoepoxyprostaglandin $\mathrm{F} 2 \mathrm{a})$ 가 $\left[\mathrm{Ca}^{2+}\right]_{\mathrm{i}}$ 의 상승작용을 통 해 myosines light chain와 pleckstrin의 인산화를 증가시키는 우수한 혈소판 응집 유도제로 사용된다는 선행 연구와 일 치한다(Cattanco et al., 1991; Su et al., 1999). 뿐만 아니라, cyclic nulceotides는 $\mathrm{Ca}^{2+}$ 유입을 감소시키고 cAMP- 및 cGMP- 의존성 단백질 kinase를 활성화함으로써 혈소판 응 집을 억제한다고 알려져 있다(Kuo et al., 1980). 본 연구에 서, scopoletin은 혈소판에서 cAMP와 cGMP 생성을 강하 게 증가시켰고, 이 결과는 scopoletin에 의한 cyclic nucleotides의 증가가 $\left[\mathrm{Ca}^{2+}\right]_{i}$ 를 조절함으로써 혈소판 응집에 중 심적인 역할을 할 수 있음을 나타낸다. cAMP와 cGMP는 adenylyl cyclase/guanyl cyclase 또는 cyclic nucleotide phosphodiesterases (PDEs)의 활성화에 의존한다(Gao et al., 2015). $\mathrm{PDE}$ 활성의 억제는 혈소판 응집에서 cyclic nucleotides의 수준을 증가시키기에, $\mathrm{PDE}$ 억제제는 혈전증에 대한 치 료적 효과를 가질 수 있다(Haslam et al., 1999). 실제로, triflusal, cilostazol, dipyridamole과 같은 PDE 억제제는 임상 적으로 cyclic nucleotides의 생산을 증가시키는 항혈소판제 로 사용된다(Menshikov et al., 1993). 본 연구에서, scopoletin 은 cAMP와 cGMP의 생산을 증가시키는 항혈소판 물질 로서 가능성이 있으며, 그 기전을 확실히 밝히기 위해서 는 추가적인 연구가 필요하다.

혈소판에서 증가된 cAMP 및 cGMP는 VASP ser157 및 ser239의 인산화를 통해 혈소판 활성화를 억제한다고 보 고되었고, $\mathrm{VASP}$ 는 $\mathrm{cAMP} / \mathrm{cGMP}$ 의존성 $\mathrm{PKA} / \mathrm{PKG}$ 의 주된 기질로 작용하여 혈소판의 분비와 접착 특성을 조절하여 혈소판 활성화를 억제하는 것으로 알려져 있다(Wangorsch et al., 2011; Napeñas et al., 2013). 또한, VASP 인산화는 integrin $\alpha \mathrm{IIb} / \beta_{3}$ 의 활성화를 억제하여 결과적으로 혈소판 응집을 억제한다. 본 연구에서, scopoletin은 U46619에 의 해 자극된 혈소판에서 $\alpha \mathrm{IIb} / \beta_{3}$ 에 대한 fibrinogen 결합능을 
유의하게 억제하였으며, 이는 cAMP 및 cGMP 생성의 증 가와 관련이 있는 것으로 보인다. 또한, 혈소판 내 dense body로부터의 ATP 방출량 증가는 혈소판 응집의 증폭 에 관여하는 것으로 알려져 있다(Holmsen and Day, 1970; Wentworth et al., 2006). 본 연구에서, scopoletin은 ATP 방 출량을 농도 의존적으로 억제하였고, 이는 혈소판의 응집 이 증폭되는 것을 억제시키는 데 기여하였다고 생각된다. 이 결과들을 통해, 우리는 scopoletin가 U46619 유도의 사 람 혈소판 응집에 있어서 억제 효과를 가진다는 것을 분 명히 하였다. 본 연구는, scopoletin의 항혈소판 효과에 대 한 기존의 연구와 다르게, 토끼나 쥐의 혈소판이 아닌 사 람 혈소판에 대한 scopoletin의 응집억제 효과를 규명한 것이며, 혈소판 응집능 뿐 아니라 관련된 여러 인자들을 분석함으로써 기전을 확인하였기에 차별적 의미가 있다 고 사료된다(Okada et al., 1995; Wu et al., 2001).

결론적으로, scopoletin은 사람 혈소판 응집을 억제하는 유효한 물질이며, 이 작용에 있어서 세포질 내로의 $\mathrm{Ca}^{2+}$ 동원을 조절하는 것이 중요하게 작용된다고 사료된다. 따 라서, 본 연구는 scopoletin이 $\mathrm{Ca}^{2+}$ 동원의 조절을 통해 혈 소판 응집을 저해하는 효과적인 혈전 예방 및 치료제로 서의 개발 가능성이 있음을 제시한다.

\section{ACKNOWLEDGEMENT}

이 논문은 2018년도 남서울대학교 학술연구비 지원에 의해 연구되었음.

\section{CONFLICT OF INTEREST}

The authors declare no conflict of interest.

\section{REFERENCES}

Barragan P, Bouvier JL, Roquebert PO, Macaluso G, Commeau P, Comet B, Lafont A, Camoin L, Walter U, Eigenthaler M. Resistance to thienopyridines: clinical detection of coronary stent thrombosis by monitoring of vasodilator-stimulated phosphoprotein phosphorylation. Catheter Cardiovasc Interv. 2003. 59: 295-302.

Berridge MJ, Irvine RF. Inositol phosphates and cell signalling. Nature. 1989. 341: 197-205.

Calderwood DA, Shattil SJ, Ginsberg MH. Integrins and actin filaments: reciprocal regulation of cell adhesion and signaling. $\mathrm{J}$ Biol Chem. 2000. 275: 22607-22610.

Cattanco M, Tenconi PM, Lecchi A, Mannucci PM. In vitro effects of picotamide on human platelet aggregation, the release reaction and thromboxane B2 production. Thromb Res. 1991 62: 717-724.

Furuichi T, Mikoshiba K. Inositol 1, 4, 5-trisphosphate receptormediated $\mathrm{Ca}^{2+}$ signaling in the brain. J Neurochem. 1995. 64: 953-960.

Gao J, Tao J, Liang W, Zhao M, Du X, Cui S, Duan H, Kan B, Su $\mathrm{X}$, Jiang Z. Identification and characterization of phosphodiesterases that specifically degrade 3'3'-cyclic GMP-AMP. Cell Res. 2015. 25: 539-550.

Haslam RJ, Dickinson NT, Jang EK. Cyclic nucleotides and phosphodiesterases in platelets. Thromb Haemost. 1999. 82: 412 $-423$.

Holmsen H, Day HJ. The selectivity of the thrombininduced platelet release reaction: subcellular localization of released and retained constituents. J Lab Clin Med. 1970. 75: 840-855.

Horstrup K, Jablonka B, Hönig-Liedl P, Just M, Kochsiek K, Walter U. Phosphorylation of focal adhesion vasodilatorstimulated phosphoprotein at Ser157 in intact human platelets correlates with fibrinogen receptor inhibition. Eur J Biochem. 1994. 225: 21-27.

Kawada N, Uoya M, Seki S, Kuroki T, Kobayashi K. Regulation by cAMP of STAT1 activation in hepatic stellate cells. Biochem Biophys Res Commun. 1997. 233: 464-469.

Kawada T, Toyosato A, Islam MO, Yoshida Y, Imai S. cGMP-kinase mediates cGMP- and cAMP-induced $\mathrm{Ca}^{2+}$ desensitization of skinned rat artery. Eur J Pharmacol. 1997. 323: 75-82.

Kuo JF, Andersson RG, Wise BC, Mackerlova L, Salomonsson I, Brackett NL, Katoh N, Shoji M, Wrenn RW. Calciumdependent protein kinase: widespread occurrence in various tissues and phyla of the animal kingdom and comparison of effects of phospholipid, calmodulin, and trifluoperazine. Proc Natl Acad Sci. 1980. 77: 7039-7043.

Kwon HW, Lee DH. The inhibitory effects of cordycepin on phosphoproteins including PI3K, Akt, and p38. Korean J Clin Lab Sci. 2017. 49: 99-107.

Menshikov MYU, Ivanova K, Schaefer M, Drummer C, Gerzer R. Influence of the cGMP analog 8-PCPT-cGMP on agonistinduced increases in cytosolic ionized $\mathrm{Ca}^{2+}$ and on aggregation of human platelets. Eur J Pharmacol. 1993. 245: 281-284.

Napeñas J, Oost FC, DeGroot A, Loven B, Hong CH, Brennan MT, Lockhart PB, van Diermen DE. Review of postoperative bleeding risk in dental patients on antiplatelet therapy. Oral Surg Oral Med Oral Pathol Oral Radiol. 2013. 115: 491-499.

Nishikawa M, Tanaka T, Hidaka H. $\mathrm{Ca}^{2+}$-calmodulin-dependent 
phosphorylation and platelet secretion. Nature. 1980. 287: 863 -865 .

Obasi SC, Njoku OU, Obidoa O. Effects of single oral doses of scopoletin and aflatoxin B1 on the clotting time, serum cholesterol and phospholipid levels of chicks. Indian J Physiol Pharmacol. 1994. 38: 89-94.

Ohkubo S, Nakahata N, Ohizumi Y. Thromboxane $\mathrm{A}_{2}$-mediated shape change: independent of Gq-phospholipase C-- $\mathrm{Ca}^{2+}$ pathway in rabbit platelets. Br J Pharmacol. 1996. 117: 1095-1104.

Okada Y, Miyauchi N, Suzuki K, Kobayashi T, Tsutsui C, Mayuzumi K, Nishibe S, Okuyama T. Search for naturally occurring substances to prevent the complications of diabetes. II. Inhibitory effect of coumarin and flavonoid derivatives on bovine lens aldose reductase and rabbit platelet aggregation. Chem Pharm Bull. 1995. 43: 1385-7.

Okwu AK, Ullian ME, Halushka PV. Homologous desensitization of human platelet thromboxane $\mathrm{A}_{2}$ /prostaglandin $\mathrm{H}_{2}$ receptors. J Pharmacol Exp Ther. 1992. 262: 238-245.

Saitoh M, Naka M, Hidaka H. The modulatory role of myosin light chain phosphorylation in human platelet activation. Biochem Biophys Res Commun. 1986. 140: 280-287.

Schaeffer J, Blaustein MP. Platelet free calcium concentrations measured with fura- 2 are influenced by the transmembrane sodium gradient. Cell Calcium. 1989. 10: 101-113.

Smolenski A, Burkhardt AM, Eigenthaler M, Butt E, Gambaryan S, Lohmann SM, Walter U. Functional analysis of cGMPdependent protein kinases I and II as mediators of NO/cGMP effects. Naunyn Schmiedebergs Arch Pharmacol. 1998. 358: 134-139.
Su CY, Shiao MS, Wang CT. Differential effects of ganodermic acid $\mathrm{S}$ on the thromboxane $\mathrm{A}_{2}$-signaling pathways in human platelets. Biochem Pharmacol. 1999. 58: 587-595.

Towler MJ, Weathers PJ. Variations in key artemisinic and other metabolites throughout plant development in Artemisia annua L. for potential therapeutic use. Ind Crops Prod. 2015. 67: 185 -191 .

Wangorsch G, Butt E, Mark R, Hubertus K, Geiger J, Dandekar T, Dittrich M. Time-resolved in silico modeling of finetuned cAMP signaling in platelets: feedback loops, titrated phosphorylations and pharmacological modulation, BMC Syst Biol. 2011. 5: 178.

Wentworth JK, Pula G, Poole AW, Vasodilator-stimulated phosphoprotein (VASP) is phosphorylated on Ser157 by protein kinase C-dependent and -independent mechanisms in thrombinstimulated human platelets, Biochemical J. 2006. 393: 555 -564 .

Wu TS, Tsang ZJ, Wu PL, Lin FW, Li CY, Teng CM, Lee KH. New constituents and antiplatelet aggregation and anti-HIV principles of Artemisia capillaris. Bioorg Med Chem. 2001. 9: 77-83.

https://doi.org/10.15616/BSL.2019.25.2.123

Cite this article as: Lee DH. Inhibitory Effect of Scopoletin on U46619-induced Platelet Aggregation through Regulation of $\mathrm{Ca}^{2+}$ Mobilization. Biomedical Science Letters. 2019. 25: 123-130. 